\title{
Direct Synthesis of Bulk Boron-Doped Graphitic Carbon
}

Nicholas P. Stadie, ${ }^{*},{ }^{\dagger, \ddagger}, \# \odot$ Emanuel Billeter, ${ }^{\dagger}$ Laura Piveteau, ${ }^{\dagger}$ Kostiantyn V. Kravchyk, ${ }^{\dagger, \ddagger}$ Max Döbeli, ${ }^{\S}$ and Maksym V. Kovalenko*, ${ }^{*},+$ (1)

${ }^{\dagger}$ Laboratory of Inorganic Chemistry, ETH Zürich, Vladimir-Prelog-Weg-1, CH-8093 Zürich, Switzerland

\#Empa - Swiss Federal Laboratories for Materials Science \& Technology, Überlandstrasse 129, CH-8600 Dübendorf, Switzerland

${ }^{\S}$ Laboratory of Ion Beam Physics, ETH Zürich, Otto-Stern-Weg 5, CH-8093 Zürich, Switzerland

\section{Supporting Information}

ABSTRACT: The single-step reaction of benzene and boron tribromide in a closed reactor at elevated temperature $\left(800{ }^{\circ} \mathrm{C}\right)$ results in the synthesis of bulk boron-doped graphitic carbon. Materials of continuously tunable composition $\mathrm{BC}_{x}{ }^{\prime}$ are accessible $(x \geq 3)$, exhibiting the structure of a solid-solution of boron within turbostratic graphite $\left(G^{\prime}\right)$. Upon extended heat treatment or at higher temperatures, graphitic $\mathrm{BC}_{x}{ }^{\prime}$ is leached of boron and undergoes a phase separation into boron carbide and graphite. Higher boron content is correlated with an increased maximum capacity for alkali metal ions, making graphitic $\mathrm{BC}_{x}{ }^{\prime}$ a promising candidate anode material for emerging sodium-ion batteries.

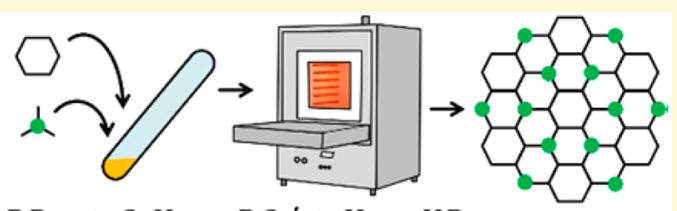

$\mathrm{BBr}_{3}+\mathrm{C}_{6} \mathrm{H}_{6} \rightarrow \mathrm{BC}_{x}{ }^{\prime}+\mathrm{H}_{2}+\mathrm{HBr}$

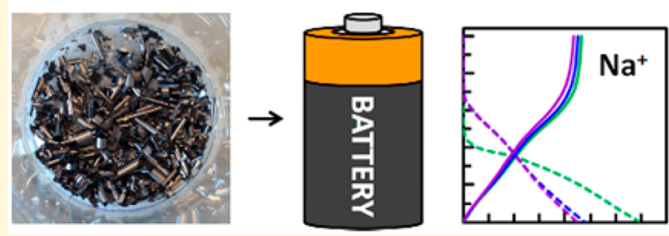

\section{INTRODUCTION}

Graphite, the stable allotrope of carbon at ambient conditions, has an archetypical layered crystal structure, a semimetallic electronic band structure, and extremely high chemical and heat resistance, and therefore wide-ranging fundamental and technological applications. Its well-known intercalation compounds, especially of alkali and alkaline earth metals, are of particular interest in energy storage applications (e.g., as the anode material in lithium-ion batteries). The substitution of carbon within the graphitic lattice by heteroatom dopants (especially neighboring elements boron and nitrogen) has been investigated for over 50 years as a route to adjust the physical and electrochemical properties of graphite. ${ }^{1-3}$ In particular, the substitution of carbon by boron can be seen as a simple chemical method to introduce electron deficiency into graphite, lowering the Fermi level as in a p-doped semiconductor and leading, for example, to an increased capacity for intercalated alkali metal ions. ${ }^{4,5}$ Structural changes in the graphite structure are also inherent to boron substitution, due to a difference in bond length and a softening of the bond character. Despite such changes, the carbon-boron binary phase diagram is notable for the high solid solubility of its constituents within the primary ambient-pressure phases: graphite, $\beta$-rhombohedral boron, and boron carbide, as shown in Figure 1.

Solid-solutions of boron in graphite were first reported by Lowell in 1967; a maximum of 2.35 atom \% B could be incorporated into graphite by annealing physical mixtures of graphite and boron carbide at temperatures up to $2500{ }^{\circ} \mathrm{C}$. ${ }^{1}$ Soobtained materials are referred to herein as equilibrium borondoped graphite, $\mathrm{BC}_{x}$. These findings were seemingly upended by Kouvetakis and co-workers in 1986, when a much higher

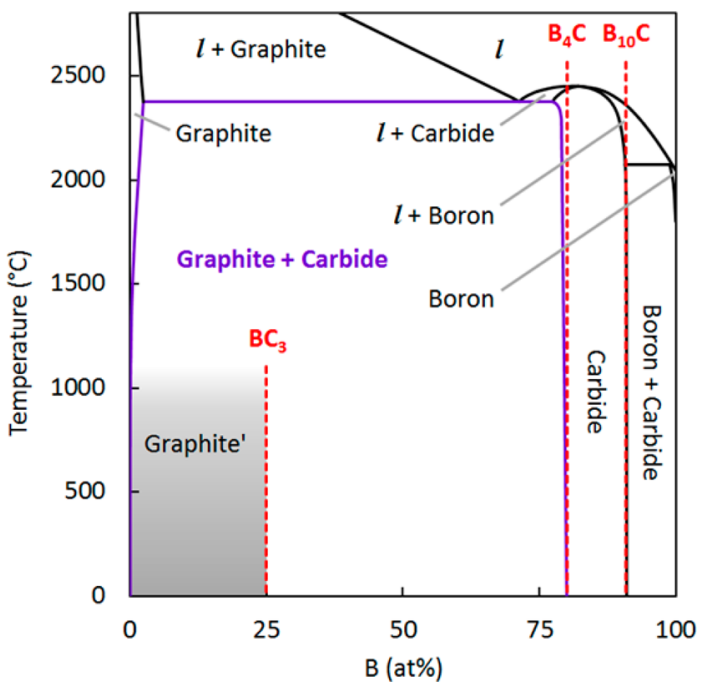

Figure 1. Boron-carbon binary phase diagram, ${ }^{1,7}$ at ambient pressure, comprising the following distinct phases: graphite (Graphite), boron carbide (Carbide), $\beta$-rhombohedral boron (Boron), and liquid $(l)$. Metastable, boron-doped graphitic carbon is also shown (Graphite').

solubility of 25 atom \% boron within polycrystalline graphite thin-films was reported. ${ }^{6}$ In this case, nonequilibrium, bottomup synthesis methods were employed by reacting benzene and $\mathrm{BCl}_{3}$ on the surface of a silica substrate under chemical vapor

Received: January 27, 2017

Revised: March 6, 2017

Published: March 11, 2017 
deposition (CVD) conditions at $800{ }^{\circ} \mathrm{C}$. The compound corresponding to highest boron content, having the approximate composition $\mathrm{BC}_{3}$, was determined to have a layered structure similar to graphite but of significant turbostratic nature. Other similar routes to thin-films of boron-containing graphitic carbon via the CVD of benzene $/ \mathrm{BCl}_{3}$, ${ }^{8,9}$ acetylene/ $\mathrm{BCl}_{3}{ }^{10}$ and triphenyl boron ${ }^{11}$ were also subsequently reported. All such syntheses of high boron content materials were performed at temperatures of $\leq 1000{ }^{\circ} \mathrm{C}$ to take advantage of kinetically hindered, nonequilibrium states. At higher temperatures, a phase separation into boron carbide and graphite occurs, leading to the conclusion that graphitic $\mathrm{BC}_{x}$ with $3 \leq x$ $<39(2.35-25$ atom \% boron) is a metastable compound of a fundamentally different type than that of boron-poor compositions $\left(<2.35\right.$ atom \% boron). ${ }^{12}$ Therefore, CVDobtained graphitic thin-films of high boron content and significantly higher structural disorder than equilibrium $\mathrm{BC}_{x}$ are referred to herein as thin-film $\mathrm{BC}_{x}{ }^{\prime}$.

The 1986 discovery of thin-film $\mathrm{BC}_{3}{ }^{6}$ has led to three decades of interest in finding a route to the corresponding bulk (free-standing) material and especially with the goal of obtaining an ordered, crystalline structure with one of the multiple low energy stacking sequences predicted by ab initio calculations. ${ }^{13}$ This endeavor has largely been inspired by numerous promising properties of such a theoretical material: unique electronic properties, ${ }^{13}$ desirable hydrogen absorption characteristics under mild conditions, ${ }^{14,15}$ and vastly increased capacity for alkali metal ion intercalation. ${ }^{16-18}$ In 2015, a synthetic route to a bulk $\mathrm{BC}_{x}{ }^{\prime}$ material of composition $x \approx 3$ was reported by King and co-workers, via a molecular tiling strategy. ${ }^{19}$ This material, referred to herein as tiled $\mathrm{BC}_{x}{ }^{\prime}$, did not meet the expectations of the hypothetical ordered $\mathrm{BC}_{3}$ material predicted by theory, owing to a high degree of structural disorder as apparent by diffraction and spectroscopy characterization techniques. However, the potential shortcomings of that synthetic approach are multifold, in particular with respect to the long time, high cost, and significant likelihood of oxygen incorporation during the 2-3 step organic synthesis of the molecular tile precursor.

In this work, we present a novel direct synthesis route to bulk, high boron-content graphitic carbon $\left(\mathrm{BC}_{x}{ }^{\prime}\right)$ and describe its properties and potential applications. Two readily available liquid precursors were selected as the sources of boron and carbon: boron tribromide $\left(\mathrm{BBr}_{3}\right)$ and benzene, respectively. Oxygen-free solutions containing the desired $\mathrm{B}: \mathrm{C}$ ratio corresponding to $x \geq 3$ could be directly pyrolyzed in a sealed quartz tube at elevated temperatures, and the resulting bulk products were investigated. The materials obtained were turbostratic graphitic carbon of widely tunable boron concentration: i.e., bulk $\mathrm{BC}_{x}{ }^{\prime}$. Their structure and composition were deduced by a combination of X-ray diffraction (XRD), Raman, and solid-state NMR spectroscopy and heavy-ion elastic recoil detection analysis (ERDA), showing significant improvements in structural order and purity over that of tiled $\mathrm{BC}_{x}{ }^{\prime}$. Finally, investigations of alkali metal ion insertion in directly synthesized bulk $\mathrm{BC}_{x}{ }^{\prime}$ are presented, and a potential application in sodium-ion batteries (SIBs) is discussed.

\section{EXPERIMENTAL SECTION}

Materials. The following materials were obtained for routine comparison to directly synthesized $\mathrm{BC}_{x}{ }^{\prime}$ : natural Kish graphite (grade 200, Graphene Supermarket), $\beta$-rhombohedral boron (60 mesh, Johnson Matthey), boron carbide (325 mesh, Johnson Matthey), disordered carbon (prepared by the direct pyrolysis of pure benzene in a closed quartz tube at $800{ }^{\circ} \mathrm{C}$ for $1 \mathrm{~h}$ via a $60{ }^{\circ} \mathrm{C} \mathrm{h}^{-1}$ ramp, identically to that of directly synthesized $\mathrm{BC}_{x}{ }^{\prime}$ with $x=\infty$ ), and tiled $\mathrm{BC}_{3}{ }^{\prime}$ (prepared by the method described elsewhere ${ }^{19}$ ). The following materials were used to prepare the electrochemical cells: stainless steel coin cell cases (CR2032, Hohsen Corp.), lithium foil (0.17 mm thick, MTI Corp.), sodium metal (ACS reagent grade, dry, Sigma-Aldrich), glass microfiber filters $(0.7 \mathrm{~mm}$ thick, $25.7 \mathrm{~mm}$ diameter, GF/D grade, no. 1823-257, Whatman), ethylene carbonate (EC, $<20 \mathrm{ppm}$ of $\mathrm{H}_{2} \mathrm{O}$, Novolyte), dimethyl carbonate (DMC, $<20$ ppm of $\mathrm{H}_{2} \mathrm{O}$, Novolyte), and propylene carbonate ( $\mathrm{PC},<20 \mathrm{ppm}$ of $\mathrm{H}_{2} \mathrm{O}$, Novolyte).

Direct Synthesis of Bulk $\mathrm{BC}_{x}{ }^{\prime}$. A solution of boron tribromide (99.9\%, Acros Organics) and benzene (anhydrous 99.8\%, Alfa Aesar) was charged into a quartz reaction tube $(20 \mathrm{~cm}$ length, $1.6 \mathrm{~cm}$ inner diameter, closed at one end) inside a glovebox under inert $\mathrm{Ar}$ atmosphere $\left(<0.1 \mathrm{ppm}\right.$ of $\mathrm{H}_{2} \mathrm{O},<0.1 \mathrm{ppm}$ of $\left.\mathrm{O}_{2}\right)$. The volume ratio of $\mathrm{BBr}_{3}: \mathrm{C}_{6} \mathrm{H}_{6}$ was determined by eq 2 (e.g., $265: 124 \mu \mathrm{L}$ for $\mathrm{BC}_{3}{ }^{\prime}$ ). The open end of the tube was closed with a Swagelok Ultra-Torr adaptor, removed from the glovebox, and connected to a stainless steel Schlenk line. The tube was evacuated to $10^{-2} \mathrm{mbar}$ with the lower half submersed in liquid nitrogen and then flame-sealed under vacuum. The sealed tube was placed within the $25 \mathrm{~cm}$ uniform temperature zone of a horizontal tube furnace (Gero FST 13/70/500) and heated to the temperature set point via a $60{ }^{\circ} \mathrm{C} \mathrm{h}^{-1}$ ramp. The set temperature was held for $1-24 \mathrm{~h}$ and then slowly cooled to $150{ }^{\circ} \mathrm{C}$ at which point the oven was opened and the tube removed. After cooling to ambient, the tube was carefully opened by a diamond-bladed saw, releasing the overpressure of gaseous reaction products into a fume hood (caution: care should be exercised in this step as $\mathrm{HBr}$ is released). The solid product was removed, washed with deionized water, acetone, and then water again, and then dried under vacuum at $150{ }^{\circ} \mathrm{C}$ before further analysis. Typical yields ranged from 30 to 150 mg per batch (see Figure S1).

Materials Characterization. Powder X-ray diffraction (XRD) measurements were performed on a STOE STADI P diffractometer using $\mathrm{Cu} \mathrm{K} \alpha_{1}$ radiation $(\lambda=1.54 \AA)$. Scanning electron microscopy (SEM) was performed using an FEI Quanta 200F microscope operated at $1 \mathrm{kV}$. Samples were prepared for SEM by depositing onto carbon foil on an aluminum plate and investigated without further coating. Raman spectroscopy was performed using a high-resolution confocal microscope (Ntegra Spectra, NTMDT Inc.) equipped with a $632.8 \mathrm{~nm} \mathrm{HeNe}$ laser at an incident power of $1.7 \mathrm{~mW}$ for excitation at room temperature. Nitrogen adsorption isotherms were measured at $77 \mathrm{~K}$ between $10^{-3}$ and $100 \mathrm{kPa}$ using an automated volumetric instrument (BELSORP-Mini, BEL Japan Inc.). Surface areas were calculated by the Brunauer-Emmett-Teller (BET) method between $P / P_{0}=0.005-0.2$.

Solid-State NMR. ${ }^{11} \mathrm{~B}$ and ${ }^{13} \mathrm{C}$ solid-state NMR experiments were performed using a Bruker 16.4 $\mathrm{T}$ spectrometer equipped with a conventional $2.5 \mathrm{~mm}$ double resonance narrow-bore MAS probe and an Avance III console. The sample was prepared by grinding in acetone, dried, filled into a $2.5 \mathrm{~mm}$ zirconia rotor, and measured at room temperature with a MAS frequency of up to $20 \mathrm{kHz}$. The MQMAS spectrum was acquired with a triple-quantum (3Q) MAS pulse sequence for odd half-integer spins (from the Bruker programs list) consisting of 3 pulses, with full echo acquisition and using a split$t_{1}$ mode: ${ }^{20}$ [excitation $-t_{1}(3 Q)-$ conversion - opt.t. $t_{1}(1 Q)-\tau-\pi_{\text {selective }}-$ acquisition]. Calibration of the indirect dimension was performed according to the previously established procedures. ${ }^{21}$ Detailed measurement parameters are given in Tables S1-S3 in the Supporting Information. The ${ }^{11} \mathrm{~B}$ chemical shift was determined with reference to $\mathrm{BF}_{3}$ ethyl etherate. ${ }^{22}$

Elemental Analysis. Elemental composition was investigated by heavy-ion elastic recoil detection analysis (ERDA) under a beam of ${ }^{127} \mathrm{I}^{-}$ions at $13 \mathrm{MeV}$. The samples were prepared by mounting with cyanoacrylate glue on an aluminum plate, using large flakes (up to $1 \times$ $1 \mathrm{~cm}$ ) that covered the glue from exposure to the beam. The angle of incidence was $18^{\circ}$ with respect to the sample surface, and the scattering angle was $36^{\circ}$. Scattered recoils were identified by a combination of a time-of-flight spectrometer with a gas ionization 
chamber, as reported elsewhere. ${ }^{23}$ The $\mathrm{C}: \mathrm{B}$ ratio was determined by fitting the ${ }^{10} \mathrm{~B},{ }^{11} \mathrm{~B}$, and ${ }^{12} \mathrm{C}$ peaks with exponentially modified Gaussian distributions. The ${ }^{10} \mathrm{~B}:{ }^{11} \mathrm{~B}$ isotopic ratio was fixed according to the measured value obtained for boron nitride as an external standard (1:4.4), and the integrated intensity of ${ }^{10} \mathrm{~B},{ }^{11} \mathrm{~B}$, and ${ }^{12} \mathrm{C}$ was converted into relative composition using their unscreened recoil cross sections.

Electrochemical Characterization. Coin-type LIB and SIB cells were assembled in a glovebox under inert Ar atmosphere $(<1 \mathrm{ppm}$ of $\mathrm{H}_{2} \mathrm{O},<1 \mathrm{ppm}$ of $\mathrm{O}_{2}$ ) using a single layer glass microfiber separator between the electrodes. Large, neat flakes of bulk $\mathrm{BC}_{x}{ }^{\prime}$ served as the working electrode, and metallic lithium (for LIBs) or sodium (for SIBs) served as both the reference and counter electrode in each cell. Common nonaqueous electrolytes were selected: $1 \mathrm{M} \mathrm{LiPF}_{6}$ in EC:DMC (1:1 by volume) for LIBs and $1 \mathrm{M} \mathrm{NaClO}_{4}$ in PC for SIBs. Cells were electrochemically cycled between 0.01 and $2.50 \mathrm{~V}$ using a multichannel workstation (Lanhe CT2001A). The measured charge capacities were normalized by the total mass of active material $(\sim 1 \mathrm{mg}$ $\mathrm{cm}^{-2}$, no binder or conductive additive were used).

\section{RESULTS}

Synthesis. A single-step approach to achieve bulk graphitic $\mathrm{BC}_{x}{ }^{\prime}$ materials of tunable composition from two readily available, miscible liquid precursors is presented. The neat liquids, benzene and $\mathrm{BBr}_{3}$, can simply be combined at room temperature in the desired $\mathrm{B}: \mathrm{C}$ molar ratio of the final product for compositions of $x \geq 3$. This homogeneous mixture is then sealed inside an evacuated quartz tube of appropriate volume (to accommodate the release of gaseous byproducts) and uniformly heated to pyrolysis temperature. The proposed reaction scheme is

$$
\frac{x}{6} \mathrm{C}_{6} \mathrm{H}_{6}+\mathrm{BBr}_{3} \rightarrow \mathrm{BC}_{x}{ }^{\prime}+3 \mathrm{HBr}+\left(\frac{x-3}{2}\right) \mathrm{H}_{2}
$$

Upon heating beyond $550{ }^{\circ} \mathrm{C}$, significant pyrolysis is visibly apparent, but conversion to a product with metallic appearance (within $1 \mathrm{~h}$ ) does not occur below $800{ }^{\circ} \mathrm{C}$. Upon cooling and opening the reactor, a significant overpressure consisting of dense vapors of $\mathrm{HBr}$ is released. The product can then simply be collected, washed, and dried for further analysis. In a typical synthesis, the quartz reactor is heated at $60{ }^{\circ} \mathrm{C} \mathrm{h}^{-1}$ up to 800 ${ }^{\circ} \mathrm{C}$, held for $1 \mathrm{~h}$, and then cooled to ambient temperature at no specific rate, culminating in a total duration of $<24 \mathrm{~h}$ from initial solution preparation to collection of the final product. The directly synthesized $\mathrm{BC}_{x}{ }^{\prime}$, obtained in quantitative yield, is simply washed and recovered in the form of $0.1-1 \mathrm{~cm}$ flakes (2-5 $\mu \mathrm{m}$ thick) with a dark metallic luster as shown in Figure 2. High symmetry hexagonal structures could be observed on the smooth outer surface of the flakes, indicating regions of well-ordered structure. The initial B:C ratio in the liquid reaction mixture (as a function of the volumes of the precursors) is used herein as the nominal composition of the final material, $\mathrm{BC}_{x}{ }^{\prime}$. It is determined by the simple expression

$$
x=6.38 \frac{V_{\text {benzene }}}{V_{\mathrm{BBr}_{3}}} \pm 5.1 \%
$$

The error in this nominal composition is determined by the pipet used to measure the precursor volumes. The model material, that of nominal precursor ratio corresponding to $x=3$ and synthesized at $800{ }^{\circ} \mathrm{C}$ for $1 \mathrm{~h}$, has the darkest, reflective black appearance and is referred to hereafter as directly synthesized $\mathrm{BC}_{3}{ }^{\prime}$.

Structure. The X-ray diffraction (XRD) pattern of directly synthesized $\mathrm{BC}_{3}{ }^{\prime}$ shows the characteristic features of turbos-
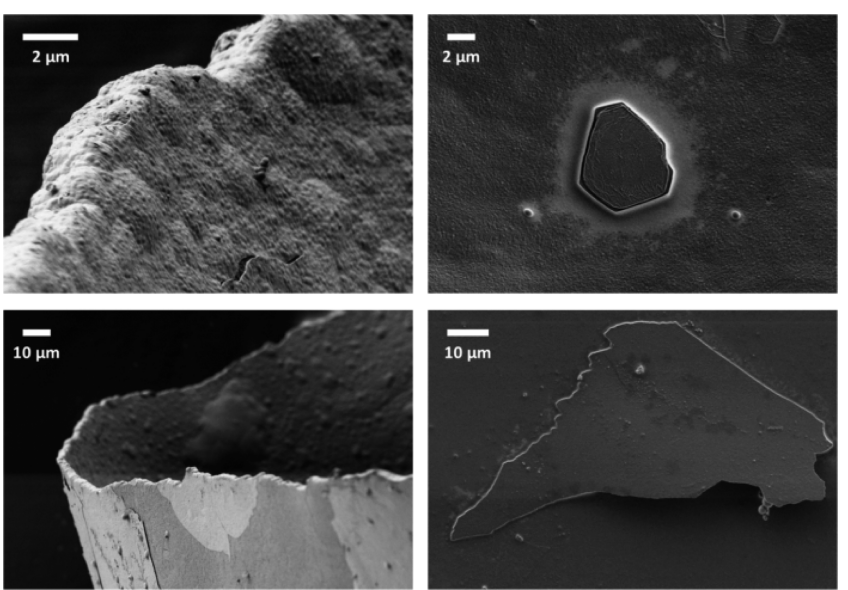

Figure 2. Typical SEM micrographs of $\mathrm{BC}_{3}{ }^{\prime}$ synthesized at $800{ }^{\circ} \mathrm{C}$.

tratic graphite with an average interlayer spacing of $3.5 \AA$ (see Figure 3). Importantly, no other crystalline phases are present. The broadness of the (002) peak between 20 and $30^{\circ}$ in $2 \theta$ (fwhm of $4.1^{\circ}$ ) is indicative of significant disorder in the interlayer spacing, a sign of incomplete graphitization that is also consistent with structural inhomogeneities arising from boron substitution within the graphitic lattice. In samples pyrolyzed at higher temperatures (e.g., at $1050{ }^{\circ} \mathrm{C}$ for $1 \mathrm{~h}$ ), the fwhm of the (002) peak is reduced to $3.0^{\circ}$ indicating higher structural order, but extended treatment at high temperature (e.g., at $1050{ }^{\circ} \mathrm{C}$ for $24 \mathrm{~h}$ ) results in the formation of boron carbide. A low specific surface area of $7-9 \mathrm{~m}^{2} \mathrm{~g}^{-1}$ was measured by $\mathrm{N}_{2}$ adsorption at $77 \mathrm{~K}$ for all samples of $\mathrm{BC}_{x}{ }^{\prime}$ tested, which is comparable to typical samples of polycrystalline graphite. ${ }^{24}$ The ${ }^{13} \mathrm{C}$ MAS NMR spectrum of directly synthesized $\mathrm{BC}_{3}{ }^{\prime}$ is also typical of polycrystalline graphitic carbon, showing a single broad feature centered at $123 \mathrm{ppm}$ which is indicative of exclusively $\mathrm{sp}^{2}$-hybridization (Figure S2).

Composition. The elemental composition of directly synthesized $\mathrm{BC}_{x}{ }^{\prime}$ is not easily discernible by typical methods such as energy-dispersive $\mathrm{X}$-ray spectroscopy (EDX), X-ray photoelectron spectroscopy (XPS), or electron energy-loss spectroscopy (EELS) owing to the similar chemical nature of boron and carbon and the bulk nature of the material (i.e., being too thick for EELS or XPS). Heavy-ion elastic recoil detection analysis (ERDA), however, presents a powerful technique for the detection of light element compositions in bulk materials, yielding depth profile information up to $250 \mathrm{~nm}$ below the surface. ${ }^{25}$ The results of ERDA experiments of $\mathrm{BC}_{x}{ }^{\prime}$ under a beam of ${ }^{127} \mathrm{I}^{-}$projectiles at $13 \mathrm{MeV}$ are shown in Figure 4. The molar ratio of carbon to boron is measured to be $5.2 \pm 1.0,8.0 \pm 1.8$, and $10.3 \pm 4.2$ for samples of nominal composition $\mathrm{BC}_{3}{ }^{\prime}, \mathrm{BC}_{7}{ }^{\prime}$, and $\mathrm{BC}_{11}{ }^{\prime}$, respectively (where the error is inherently larger for higher values of $x$ but is roughly similar in units of atom \% boron). Identical measurements of a boron carbide standard $\left(\mathrm{B}_{12} \mathrm{C}_{3}\right)$ give a boron to carbon ratio of $2.5 \pm 0.2$ instead of the nominal 4; therefore, "corrected" ERDA elemental compositions are also shown in Figure 4 that account for the difference in the measured and nominal composition of the $\mathrm{B}_{12} \mathrm{C}_{3}$ standard. The highest corrected boron content is exhibited by $\mathrm{BC}_{3}{ }^{\prime}$ synthesized for $1 \mathrm{~h}$ at 800 ${ }^{\circ} \mathrm{C}$, with an average composition over numerous samples corresponding to $x=3.2$. Samples synthesized at higher temperature (e.g., for $1 \mathrm{~h}$ at $1050{ }^{\circ} \mathrm{C}$ ) show a lower content of boron by ERDA methods, e.g., corresponding to $x=4.5-7.3$ 

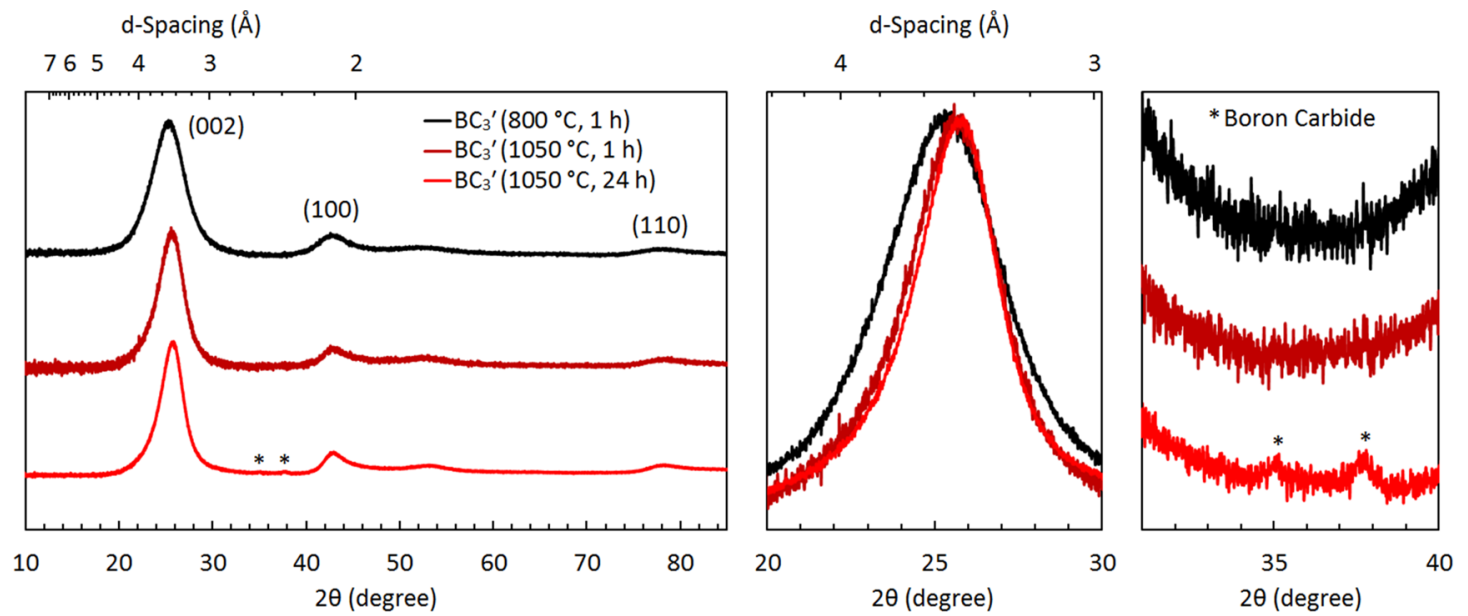

Figure 3. XRD patterns of $\mathrm{BC}_{3}{ }^{\prime}$ synthesized at 800 and $1050{ }^{\circ} \mathrm{C}$ for $1 \mathrm{~h}$. Samples held at $1050{ }^{\circ} \mathrm{C}$ for $24 \mathrm{~h}$ showed evidence of boron carbide formation (indicated by asterisks).

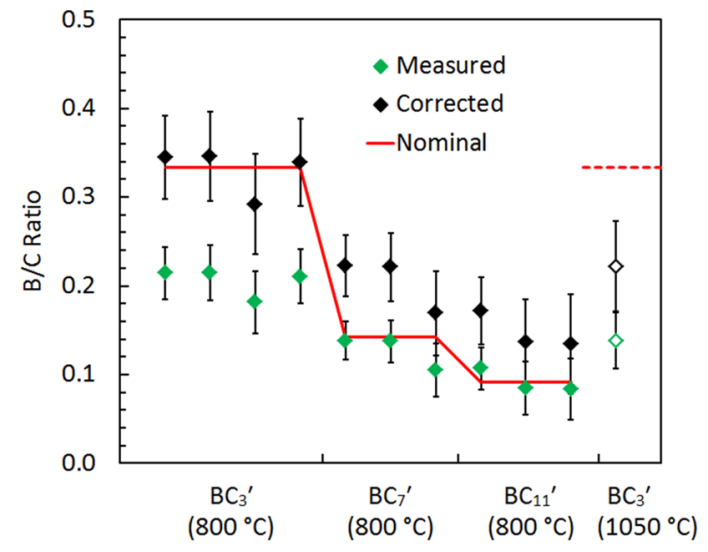

Figure 4. Elemental composition of $\mathrm{BC}_{x}{ }^{\prime}$ samples synthesized at 800 ${ }^{\circ} \mathrm{C}$ (filled symbols) or $1050{ }^{\circ} \mathrm{C}$ (empty symbols) as determined by ERDA using ${ }^{127} \mathrm{I}^{-}$projectiles. The corrected values (black) are calculated based on calibration using a boron carbide standard.

(see Figure 4). Overall, a modest agreement exists between the nominal composition and the measured/corrected compositions for all samples of $\mathrm{BC}_{x}{ }^{\prime}$. Oxygen contents of up to 7 atom $\%$ are also detected, consistent with that found in disordered carbon synthesized from pure benzene in the same conditions and typical of most carbonaceous materials synthesized at temperatures below $1000{ }^{\circ} \mathrm{C}$.

Boron Environment. The nature of boron inclusion within directly synthesized $\mathrm{BC}_{x}{ }^{\prime}$ has been examined herein by a combination of solid-state NMR and Raman spectroscopy measurements. The ${ }^{11} \mathrm{~B}$ multiple-quantum magic-angle spinning $\left(\right.$ MQMAS $\left.^{26}\right)$ NMR spectrum of directly synthesized $\mathrm{BC}_{3}{ }^{\prime}$ is shown in Figure 5. Two distinct signals are observed with isotropic shifts at 30 and $19 \mathrm{ppm}$. They show only little quadrupolar broadening and some isotropic broadening due to site disorder. The isotropic quadrupole contribution induces a shift of 5 ppm in both signals. The dominant chemical shift region around $30 \mathrm{ppm}$ corresponds to the chemical environment of B-C bonding in trigonal planar symmetry, ${ }^{19,45}$ especially with more electronegative carbon types ${ }^{27}$ (i.e., $\mathrm{sp}^{2}$ carbon rather than $\mathrm{sp}^{3}$ ). Contributions from $\mathrm{B}-\mathrm{O}$ bonding in trigonal planar symmetry are consistent with the secondary signal around $19 \mathrm{ppm}$ (expected at $0-20 \mathrm{ppm}$ at $16.1 \mathrm{~T}){ }^{28,29}$ Bonding to bromine cannot be completely ruled out (expected

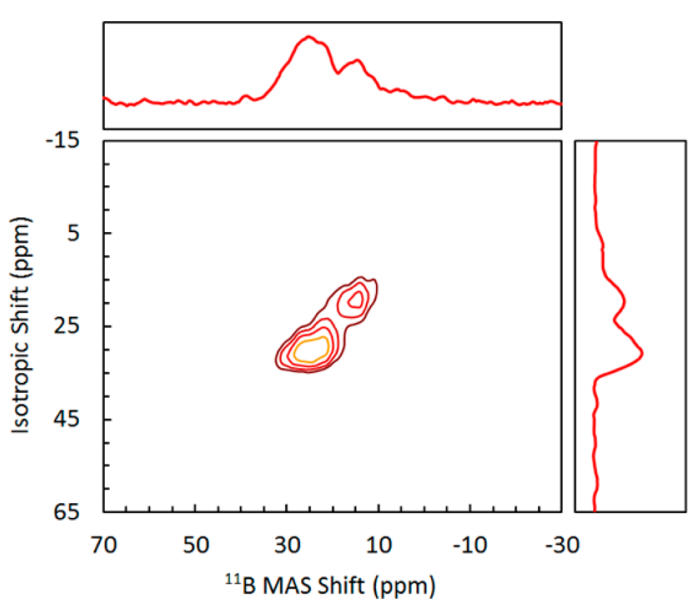

Figure 5. ${ }^{11} \mathrm{~B}$ MQMAS NMR spectrum of $\mathrm{BC}_{3}{ }^{\prime}$ synthesized at $800{ }^{\circ} \mathrm{C}$ (color indicates higher intensity from dark red to orange). Calibration of the indirect dimension was performed as described by Amoureux and Fernandez. ${ }^{21}$

at $\sim 40 \mathrm{ppm}$ for $\mathrm{BBr}_{3}$ in the liquid-state ${ }^{30}$ ). Other chemical environments of boron such as tetrahedral $\mathrm{B}-\mathrm{O}$ bonding and icosahedral $\mathrm{B}-\mathrm{B}$ units (as in $\beta$-rhombohedral boron) are not present in directly synthesized $\mathrm{BC}_{3}{ }^{\prime}$ (expected at $<0 \mathrm{ppm}$ for tetrahedral $\mathrm{B}-\mathrm{O}$ groups $^{28}$ and $\sim 0$ ppm for $\mathrm{B}-\mathrm{B}$ icosahedra, ${ }^{31}$ all with reference to $\mathrm{BF}_{3}$ ethyl etherate).

Raman spectra of directly synthesized $\mathrm{BC}_{x}{ }^{\prime}$ materials of increasing boron content are shown in Figure 6. The characteristic features of disordered or nanocrystalline graphitic carbon $^{32}$ are present in all spectra, as labeled, in stark contrast to the crystalline graphite reference. These include a dominant G band at $1591 \mathrm{~cm}^{-1}$, a significant $\mathrm{D}$ band at $1368 \mathrm{~cm}^{-1}$, and a broad feature between 2300 and $3300 \mathrm{~cm}^{-1}$ corresponding to a combination of second-order bands including the disorderinduced $2 \mathrm{D}$ (also referred to as " $G^{\prime \prime 33}$ ), $\mathrm{D}+\mathrm{D}^{\prime}$, and $2 \mathrm{D}^{\prime}$ bands. The intensity ratio between the $\mathrm{D}$ and $\mathrm{G}$ bands $\left(I_{\mathrm{D}} / I_{\mathrm{G}}\right)$ decreases with boron content, from 0.81 for disordered carbon (synthesized by the direct pyrolysis of pure benzene at $800{ }^{\circ} \mathrm{C}$ ) to 0.75 for $\mathrm{BC}_{3}{ }^{\prime}$ (Figure S7). These $I_{\mathrm{D}} / I_{\mathrm{G}}$ values, in combination with a $\mathrm{G}$ band position of $\sim 1590 \mathrm{~cm}^{-1}$, indicate that all directly synthesized $\mathrm{BC}_{x}{ }^{\prime}$ materials fall into the category between nanocrystalline and ordered graphite as opposed to strictly amorphous carbon (within "stage 1" in the Ferrari and 

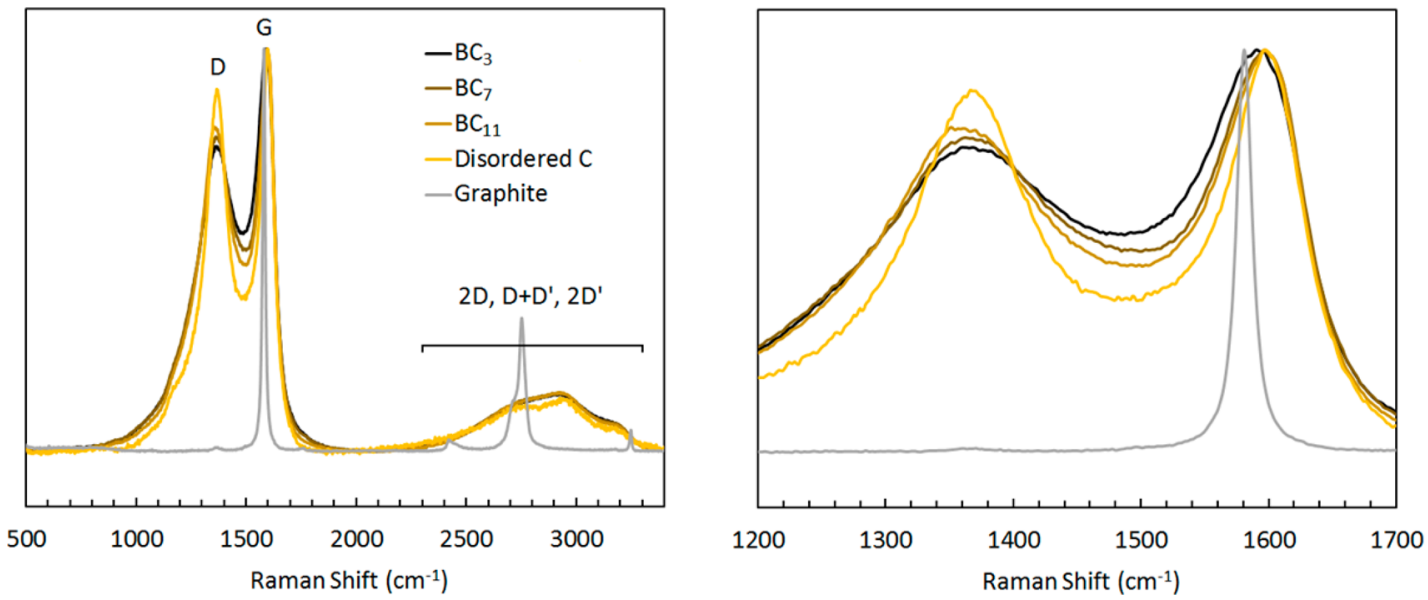

Figure 6. Raman spectra of $\mathrm{BC}_{x}{ }^{\prime}$ synthesized at $800{ }^{\circ} \mathrm{C}: \mathrm{BC}_{3}{ }^{\prime}$ (black), $\mathrm{BC}_{7}{ }^{\prime}$ (brown), and $\mathrm{BC}_{11}{ }^{\prime}$ (light brown). Disordered carbon, prepared by the pyrolysis of pure benzene at $800{ }^{\circ} \mathrm{C}$ (yellow), and graphite (gray) are also shown for reference.

Robertson three-stage model). ${ }^{34}$ Importantly, no intense bands corresponding to icosahedral boron-boron bonding, such as in elemental boron or boron carbide, are present in $\mathrm{BC}_{x}{ }^{\prime}$ (with significant intensity between 700 and $800 \mathrm{~cm}^{-1}$, see Figure S3).

Alkali Metal Ion Insertion. The electrochemical insertion of alkali metal ions into directly synthesized $\mathrm{BC}_{x}{ }^{\prime}$, as investigated by galvanostatic cycling in common battery electrolytes against the native metal counter/reference electrode, is found to proceed by a primarily capacitive (i.e., non-Faradaic) mechanism for lithium, sodium, and potassium. Both lithium and sodium insertion take place within approximately the same potential window with respect to their native metal: between 0 and $+1.8 \mathrm{~V}$, with an average charge potential of $1.0 \mathrm{~V}$ (compared to $\mathrm{Li} / \mathrm{Li}^{+}$or $\mathrm{Na} / \mathrm{Na}^{+}$, respectively). The potential profiles during the first five cycles at a current rate of $100 \mathrm{~mA} \mathrm{~g}{ }^{-1}$ for lithium and sodium insertion in $\mathrm{BC}_{3}{ }^{\prime}$ are shown in Figure 7 . The reversible capacity of $\mathrm{BC}_{3}{ }^{\prime}$ for lithium and sodium ions (as approximated by the fifth cycle discharge capacity) at $100 \mathrm{~mA} \mathrm{~g}^{-1}$ is found to be 524 and $278 \mathrm{mAh} \mathrm{g}^{-1}$, respectively, corresponding to $\mathrm{Li}_{0.92} \mathrm{BC}_{3}$ and $\mathrm{Na}_{0.49} \mathrm{BC}_{3}$. Initial measurements of alkali ion insertion into directly synthesized $\mathrm{BC}_{x}{ }^{\prime}$ of varying composition show that the reversible capacity (i.e., beyond the fifth cycle) and the average potential of insertion both increase as a function of boron content, a subject of further investigation in this laboratory.

\section{DISCUSSION}

The direct pyrolysis of boron tribromide and benzene in a closed vessel at $800{ }^{\circ} \mathrm{C}$ is an exceedingly simple, one-pot, onestep route to bulk samples of high boron-content graphitic carbon, using only readily available molecular precursors. The product, $\mathrm{BC}_{x}{ }^{\prime}$, can be prepared across a range of boron compositions depending on the composition of the precursor solution and the heat treatment regimen. Beyond the optimal pyrolysis conditions of $1 \mathrm{~h}$ at $800{ }^{\circ} \mathrm{C}$, higher temperature and longer pyrolysis time lead to less boron in the graphitic phase, as evidenced by the presence of boron carbide in the XRD pattern (Figure 3, asterisks) and lower boron content in the free-standing flakes (Figure 4, open symbols). The composition of the final bulk $\mathrm{BC}_{x}{ }^{\prime}$ material can be controlled up to at least $x$ $\approx 5$, as determined by "uncorrected" ERDA measurements; corrections of the ERDA results by employing a commercial standard $\left(\mathrm{B}_{12} \mathrm{C}_{3}\right)$ give evidence for compositions up to $x=3.2$, to within an error of \pm 0.6 . These figures fall into the same general range as those reported for thin-film $\mathrm{BC}_{x}{ }^{\prime}$ materials, variously reported as limited to $x \geq 6,{ }^{35} x \geq 5^{8}$, and, as initially reported, $x \geq 3$. ${ }^{6,36,37}$ Most of the methods that were used to determine the compositions of $\mathrm{BC}_{x}{ }^{\prime}$ thin-films are not accessible or reliable for bulk materials, such as XPS and EELS, and ERDA is therefore employed herein. Nevertheless, a source of uncertainty in the ERDA experiments may lie in differences in the sample surface roughness. On a rough surface, primary beam particles and recoiling sample atoms pass through the surface over a wide distribution of angles, leading to a distortion of the measured energy spectrum and concentration depth profile. Since there is a largely different surface structure between the $\mathrm{BC}_{x}{ }^{\prime}$ samples and the $\mathrm{B}_{12} \mathrm{C}_{3}$ standard material, a systematic effect on normalization cannot be ruled out. Lastly, it is important to note that the possibility of erroneous carbon contamination from the environment greatly exceeds that of boron, implying that any estimation of the $\mathrm{B}: \mathrm{C}$ composition ratio is that of its lower limit (i.e., the upper limit of $x$ ).

The structure of directly synthesized $\mathrm{BC}_{x}{ }^{\prime}$ must be that of a solid solution of boron within highly disordered, turbostratic graphite, as determined by the combined evaluation of XRD, ERDA, and NMR/Raman spectroscopy measurements. All samples exhibit exclusively graphitic structure (by XRD analysis) and also contain a high content of boron (up to $x=$ 3.2 for $\mathrm{BC}_{3}^{\prime}$ by "corrected" ERDA measurements), significantly greater than that of equilibrium graphitic $\mathrm{BC}_{x}{ }^{1}$ (where the limit is $x=\sim 39)$. ${ }^{11} \mathrm{~B}$ NMR spectroscopy confirms the significant presence of boron in $\mathrm{BC}_{x}{ }^{\prime}$, and the maximum at $30 \mathrm{ppm}$ is most consistent with bonding to carbon within a trigonal planar (graphitic) lattice. Bonding to oxygen (in trigonal planar geometry only) is likely to contribute to some of the intensity at higher field (in the secondary chemical environment at an isotropic shift of $19 \mathrm{ppm}$ ), but bonding to boron (as in clustering or phase separated boron-rich phases) would give rise to intensity at $\sim 0 \mathrm{ppm}^{31}$ and is therefore not significant in $\mathrm{BC}_{x}{ }^{\prime}$. Any tetrahedral bonding environments can also be ruled out, and any residual $\mathrm{Br}$ content in the material is minimal (which is consistent with estimates of $<0.1$ atom \% by ERDA). Most importantly, the boron content must occupy graphitic lattice sites owing to the lack of Raman intensity corresponding to $\mathrm{B}-\mathrm{B}$ icosahedral vibrational modes (and bolstered by a lack of crystalline boron-rich phases in the XRD pattern). Although no significant shift in the prominent Raman bands is observed 

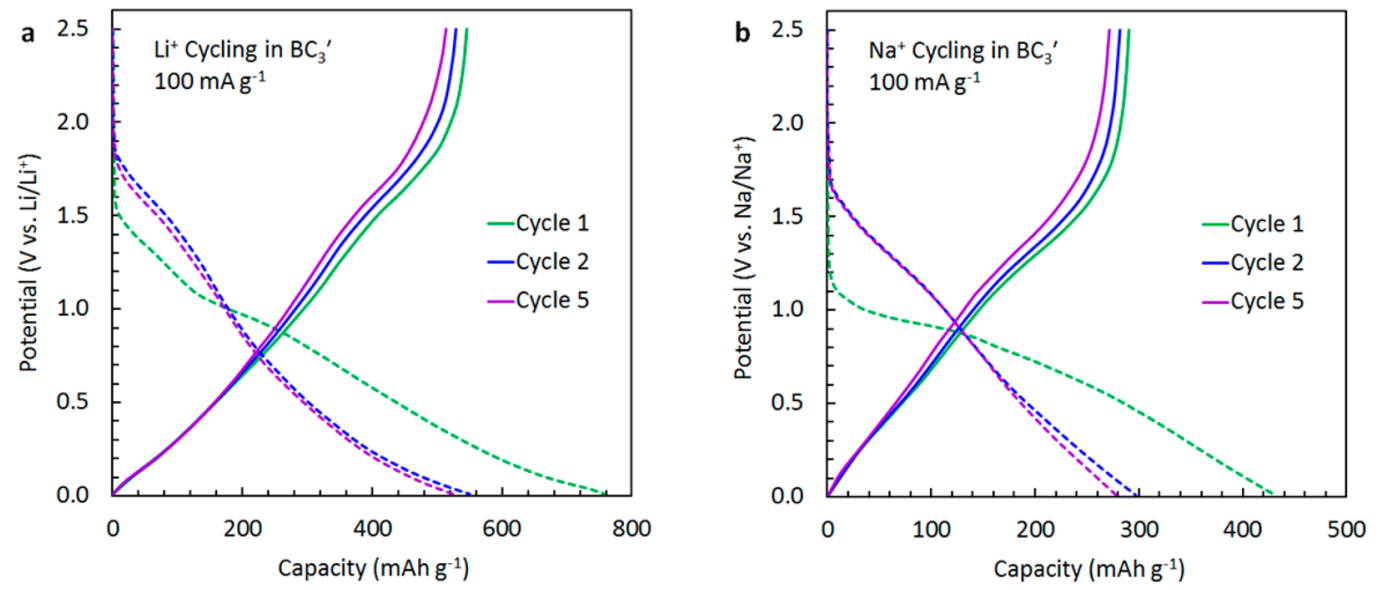

Figure 7. Electrochemical insertion of (a) lithium and (b) sodium into $\mathrm{BC}_{3}{ }^{\prime}$ over five cycles between 0.01 and $2.50 \mathrm{~V}$ (compared to the native alkali metal) at a current rate of $100 \mathrm{~mA} \mathrm{~g}^{-1}$.

due to the presence of boron in the lattice, the broad nature of the signal and the complex, competing effects of structural disorder and boron doping make this type of analysis difficult. The Raman spectra of directly synthesized $\mathrm{BC}_{x}{ }^{\prime}$ produced herein resemble those of boron-implanted graphite films prepared by ${ }^{11} \mathrm{~B}$-ion irradiation (at a fluence of $\sim 10^{15}$ ions $\mathrm{cm}^{-2}$ ), corresponding to a high overall boron content and regions of persistent graphitic structure (the "microcrystalline regime"). ${ }^{38}$ In addition, the $I_{\mathrm{D}} / I_{\mathrm{G}}$ ratio decreases with boron content as in thin-film $\mathrm{BC}_{x}{ }^{39}$ (Figure S7), an observation that is consistent with the known role of boron in the improved graphitization of carbon at lower temperatures. ${ }^{35}$

Disorder in the structure of bulk $\mathrm{BC}_{x}{ }^{\prime}$ can generally be classified as either interlayer (i.e., stacking disorder) or intralayer (e.g., boron site clustering, vacancies, folding/ crumpling, etc.), both of which are likely to increase with boron content. No evidence could be found in this work for macroscopic heterogeneities with respect to chemical composition or structure in directly synthesized $\mathrm{BC}_{3}{ }^{\prime}$. The broad line width in XRD patterns indicates a wide distribution of interlayer spacings, a potentially combined effect from interand intralayer disorder, and/or limited distances of crystallinity (as per the Scherrer equation). The two broad chemical environments deduced by ${ }^{11} \mathrm{~B}$ MQMAS NMR with isotropic shifts of 30 and $19 \mathrm{ppm}$ are consistent with multiple different stacking arrangements present within $\mathrm{BC}_{3}{ }^{\prime}$ and are also consistent with multiple distinct boron sites within the lattice (or perhaps from $\mathrm{B}-\mathrm{O}$ or $\mathrm{B}-\mathrm{Br}$ impurities). The observed isotropic broadening further indicates significant disorder on these boron sites, which can also be interpreted as stacking disorder or lattice site inhomogeneity. Likewise, an unambiguous interpretation of the type of disorder present based on the Raman spectrum is not possible, owing to the fact that boron doping exudes inherently similar vibrational effects upon the graphitic lattice as does the addition of vacancies, which has been well investigated for equilibrium $\mathrm{BC}_{x}{ }^{38,40}$

When compared to tiled $\mathrm{BC}_{3}{ }^{\prime 19}$ the only other known bulk $\mathrm{BC}_{x}{ }^{\prime}$ material, the structure and composition of directly synthesized $\mathrm{BC}_{3}{ }^{\prime}$ show a higher degree of structural and chemical homogeneity despite its shorter and simpler method of preparation. For example, the fwhm of the (002) reflection in XRD measurements is only $2 \theta=4.1^{\circ}$, compared to $7^{\circ}$ for tiled $\mathrm{BC}_{3}{ }^{\prime}$ (Figure $\mathrm{S} 4$ ), indicating higher structural regularity is achieved by the direct synthesis route. Furthermore, the $I_{\mathrm{D}} / I_{\mathrm{G}}$ ratio in the Raman spectrum, which decreases with boron content (as seen in Figure 6), is also lower in directly synthesized $\mathrm{BC}_{3}{ }^{\prime}$ (Figure S6). This increased structural order can be explained by an increased probability for successful bonding between the precursors and the crystal growth front in the case of the highly symmetrical direct synthesis precursors $\left(\mathrm{BBr}_{3}\right.$ and $\left.\mathrm{C}_{6} \mathrm{H}_{6}\right)$ as opposed to that of the tiling route $\left(\mathrm{C}_{6} \mathrm{H}_{4}\left(\mathrm{BBr}_{2}\right)_{2}\right)$. From a compositional perspective, the ${ }^{11} \mathrm{~B}$ MAS NMR spectrum of directly synthesized $\mathrm{BC}_{3}{ }^{\prime}$ clearly shows a remarkable difference compared to that achieved by tiling: the lack of a dominant peak at $\sim 14 \mathrm{ppm}$ that corresponds to $\mathrm{B}-\mathrm{O}$ bonding as found in solid-state borates such as $\mathrm{B}_{2} \mathrm{O}_{3}$ (Figure S8) or boric acid. This higher content of oxygen in the boron environment of the tiled product is likely a result of increased exposure to air over the course of its multiday synthesis. Nevertheless, the overall elemental composition of directly synthesized $\mathrm{BC}_{3}{ }^{\prime}$ is comparable to that of tiled $\mathrm{BC}_{3}{ }^{\prime}$ as determined by internal ERDA comparison herein (Figures $\mathrm{S} 8-$ S9). It should be stressed that neither material is comparable to crystalline graphite except in identifying and understanding the general structural framework present; both types of bulk $\mathrm{BC}_{3}{ }^{\prime}$ are structurally more akin to disordered, turbostratic carbon, as achieved by the direct pyrolysis of pure benzene (or other aromatic precursors ${ }^{41}$ ) under similar conditions. No bulk material reported at this time is equivalent to the hypothetical $\mathrm{BC}_{3}$ material with ordered structure that has been studied by $\mathrm{ab}$ initio methods, ${ }^{13}$ despite that its theoretical free energy (or energies, when considering the various low-energy stacking sequences) indicates that it should be experimentally attainable. Further work to achieve that end is more likely to be successful via a simple, flexible, fast, and clean synthetic route based on the method described herein.

Initial investigations of lithium and sodium insertion in directly synthesized $\mathrm{BC}_{x}{ }^{\prime}$ have shown that, in agreement with its highly disordered, turbostratic graphitic structure, the mechanism of interaction is predominantly capacitive (nonFaradaic), occurring over a wide range of potential with a high average voltage compared to the alkali metal counter electrode. This remains in stark contrast to theoretical results based on the hypothetical, crystalline $\mathrm{BC}_{3}$ structure, ${ }^{17}$ and there is no evidence herein for intercalation of ions in an interlayer staging mechanism at specific potentials. For this reason, bulk $\mathrm{BC}_{3}{ }^{\prime}$ is not a suitable candidate as an anode for lithium-ion batteries (LIBs) at this time, primarily in view of the more desirable 
lithium storage behavior of pure graphite which exhibits low voltage plateaus vs $\mathrm{Li} / \mathrm{Li}^{+}$. However, the electrochemical behavior of bulk $\mathrm{BC}_{3}{ }^{\prime}$ can be seen as analogous to hard carbon, a material which exhibits a distinct advantage over graphite in its ability to take up sodium ions (the graphite intercalation compounds of sodium are thermodynamically unstable under reasonable conditions). Sodium is known to be effectively stored within the extremely small nanocavities typically present in and between turbostratic, microcrystalline domains in the disordered graphitic structure, in accordance with the "house of cards" model. ${ }^{42}$ From this perspective, directly synthesized $\mathrm{BC}_{3}{ }^{\prime}$ demonstrates a comparable electrochemical sodium storage capacity (e.g., $278 \mathrm{mAh} \mathrm{g}^{-1}$ at $100 \mathrm{~mA}$ $\mathrm{g}^{-1}$ ) to that of state-of-the-art, hard carbon-based anodes (which range from 200 to $350 \mathrm{mAh} \mathrm{g}^{-1}$ ). ${ }^{43,44}$ Early indications that an increased capacity is correlated with increasing boron content in otherwise identical materials imply that further optimization of the nanostructure of disordered $\mathrm{BC}_{3}{ }^{\prime}$ may very well lead to much higher eventual capacities, making it a promising candidate for further investigation.

\section{CONCLUSIONS}

A bulk synthesis route to boron-doped graphitic carbon, $\mathrm{BC}_{x}{ }^{\prime}$, via the direct pyrolysis of two readily available precursors has been presented herein, providing a novel route to compositional and structural tunability in the low temperature, metastable region $\left(G^{\prime}\right)$ of the boron-carbon binary phase diagram. The material of interest, directly synthesized $\mathrm{BC}_{3}{ }^{\prime}$ obtained at $800{ }^{\circ} \mathrm{C}$ within a total of $<24 \mathrm{~h}$ from start to finish, has been shown to exhibit relatively high structural order and compositional purity compared to tiled $\mathrm{BC}_{3}{ }^{\prime}$, the only other known bulk material analogue. Boron incorporation within the graphitic lattice has been confirmed by NMR and Raman spectroscopy, although significant disorder exists in the layerto-layer stacking, a typical feature of carbon materials prepared at $<1000{ }^{\circ} \mathrm{C}$. Nevertheless, directly synthesized $\mathrm{BC}_{x}{ }^{\prime}$ exhibits a significantly higher capacity for alkali metal ions than similarly obtained pure carbon, which is consistent with ab initio predictions of the effect of boron-doping on the electrochemical properties of crystalline graphite. The non-Faradaic ion storage mechanism of $\mathrm{BC}_{3}{ }^{\prime}$ and relatively high capacity of $278 \mathrm{mAh} \mathrm{g}^{-1}$ are especially well-suited for application as the anode material in emerging sodium-ion batteries, where hard carbon is the current state-of-the-art material. Further optimization of the synthesis of bulk $\mathrm{BC}_{x}{ }^{\prime}$ within the direct route presented herein will perhaps allow the tuning of the structure and composition toward that of hypothetical, ordered $\mathrm{BC}_{3}$ that has been the subject of great theoretical and experimental interest for the last 30 years.

\section{ASSOCIATED CONTENT}

\section{S Supporting Information}

The Supporting Information is available free of charge on the ACS Publications website at DOI: 10.1021/acs.chemmater.7b00376.

Experimental NMR parameters and additional materials characterization (PDF)

\section{AUTHOR INFORMATION}

\section{Corresponding Authors}

*E-mail: nicholas.stadie@montana.edu.

*E-mail: mvkovalenko@ethz.ch.

\section{ORCID}

Nicholas P. Stadie: 0000-0002-1139-7846

Maksym V. Kovalenko: 0000-0002-6396-8938

Present Address

\#Department of Chemistry and Biochemistry, Montana State University, Bozeman, MT 59717, United States.

\section{Author Contributions}

The manuscript was written through contributions of all authors.

\section{Notes}

The authors declare no competing financial interest.

\section{ACKNOWLEDGMENTS}

We thank Frank Krumeich for performing SEM investigations and René Verel for assistance with NMR measurements and analysis, as well as Qasim Imtiaz for assistance with Raman measurements (spectrometer supplied with assistance from the Swiss National Science Foundation (SNF) R'Equip program, grant 206021_144986/1). This work was financially supported by the Swiss Federal Commission for Technology and Innovation (CTI) through the CTI Swiss Competence Centers for Energy Research (SCCER, "Heat and Electricity Storage") and through CTI Project Nr. 14698.2 PFIW-IW and by the Competence Center for Energy and Mobility (CCEM, Project SLIB).

\section{REFERENCES}

(1) Lowell, C. E. Solid Solution of Boron in Graphite. J. Am. Ceram. Soc. 1967, 50 (3), 142-144.

(2) Badyan, A.; Niemski, T.; Appenheimer, S.; Olkusnik, E. Crystal structure in the boron-carbon-nitrogen system. Khim. Svyaz Poluprovodn. Polumet. 1972, 362-366.

(3) Kaner, R. B.; Kouvetakis, J.; Warble, C. E.; Sattler, M. L.; Bartlett, N. Boron-carbon-nitrogen materials of graphite-like structure. Mater. Res. Bull. 1987, 22, 399-404.

(4) Endo, M.; Kim, C.; Karaki, T.; Nishimura, Y.; Matthews, M. J.; Brown, S. D. M.; Dresselhaus, M. S. Anode performance of a Li ion battery based on graphitized and B-doped milled mesophase pitchbased carbon fibers. Carbon 1999, 37 (4), 561-568.

(5) Endo, M.; Hayashi, T.; Hong, S.-H.; Enoki, T.; Dresselhaus, M. S. Scanning tunneling microscope study of boron-doped highly oriented pyrolytic graphite. J. Appl. Phys. 2001, 90 (11), 5670-5674.

(6) Kouvetakis, J.; Kaner, R. B.; Sattler, M. L.; Bartlett, N. A novel graphite-like material of composition $\mathrm{BC}_{3}$, and nitrogen-carbon graphites. J. Chem. Soc., Chem. Commun. 1986, 1758-1759.

(7) Okamoto, H. B-C (Boron-Carbon). J. Phase Equilib. 1992, 13 (4), 436.

(8) Way, B. M.; Dahn, J. R.; Tiedje, T.; Myrtle, K.; Kasrai, M. Preparation and characterization of $\mathrm{B}_{\mathrm{x}} \mathrm{C}_{1-\mathrm{x}}$ thin films with the graphite structure. Phys. Rev. B: Condens. Matter Mater. Phys. 1992, 46 (3), $1697-1702$.

(9) Fecko, D. L.; Jones, L. E.; Thrower, P. A. The formation and oxidation of BC3, a new graphitelike material. Carbon 1993, 31 (4), 637-644.

(10) Shirasaki, T.; Derré, A.; Ménétrier, M.; Tressaud, A.; Flandrois, S. Synthesis and characterization of boron-substituted carbons. Carbon 2000, 38, 1461-1467.

(11) Kouvetakis, J.; McElfresh, M. W.; Beach, D. B. Chemical vapor deposition of highly conductive boron-doped graphite from triphenyl boron. Carbon 1994, 32 (6), 1129-1132.

(12) Ottaviani, B.; Derré, A.; Grivei, E.; Mahmoud, O. A. M.; Guimon, M.-F.; Flandrois, S.; Delhaès, P. Boronated carbons: structural characterization and low temperature physical properties of disordered solids. J. Mater. Chem. 1998, 8 (1), 197-203. 
(13) Sun, H.; Ribeiro, F. J.; Li, J.-L.; Roundy, D.; Cohen, M. L.; Louie, S. G. Ab initio pseudopotential studies of equilibrium lattice structures and phonon modes of bulk $\mathrm{BC}_{3}$. Phys. Rev. B: Condens. Matter Mater. Phys. 2004, 69, 024110.

(14) Zhang, C.; Alavi, A. Hydrogen absorption in bulk $\mathrm{BC}_{3}$ : a firstprinciples study. J. Chem. Phys. 2007, 127, 214704.

(15) Sha, X.; Cooper, A. C., III; Bailey, W. H.; Cheng, H. Revisiting Hydrogen Storage in Bulk $\mathrm{BC}_{3}$. J. Phys. Chem. C 2010, 114, 32603264.

(16) Kuzubov, A. A.; Fedorov, A. S.; Eliseeva, N. S.; Tomilin, F. N.; Avramov, P. V.; Fedorov, D. G. High-capacity electrode material $\mathrm{BC}_{3}$ for lithium batteries proposed by ab initio simulations. Phys. Rev. B: Condens. Matter Mater. Phys. 2012, 85, 195415.

(17) Joshi, R. P.; Ozdemir, B.; Barone, V.; Peralta, J. E. Hexagonal BC3: A Robust Electrode Material for $\mathrm{Li}, \mathrm{Na}$, and $\mathrm{K}$ Ion Batteries. J. Phys. Chem. Lett. 2015, 6, 2728-2732.

(18) Liu, Y.; Artyukhov, V. I.; Liu, M.; Harutyunyan, A. R.; Yakobson, B. I. Feasibility of Lithium Storage on Graphene and Its Derivatives. J. Phys. Chem. Lett. 2013, 4 (10), 1737-1742.

(19) King, T. C.; Matthews, P. D.; Glass, H.; Cormack, J. A.; Holgado, J. P.; Leskes, M.; Griffin, J. M.; Scherman, O. A.; Barker, P. D.; Grey, C. P.; Dutton, S. E.; Lambert, R. M.; Tustin, G.; Alavi, A.; Wright, D. S. Theory and Practice: Bulk Synthesis of $\mathrm{C}_{3} \mathrm{~B}$ and its $\mathrm{H}_{2-}$ and Li-Storage Capacity. Angew. Chem., Int. Ed. 2015, 54, 5919-5923.

(20) Brown, S. P.; Wimperis, S. Two-Dimensional MultipleQuantum MAS NMR of Quadrupolar Nuclei: A Comparison of Methods. J. Magn. Reson. 1997, 128 (1), 42-61.

(21) Amoureux, J.-P.; Fernandez, C. Erratum to "Triple, quintuple and higher order multiple quantum MAS NMR of quadrupolar nuclei" [Solid State NMR 10 (1998) 211-223]. Solid State Nucl. Magn. Reson. 2000, 16 (4), 339-343.

(22) Harris, R. K.; Becker, E. D.; De Menezes, S. M. C.; Goodfellow, R.; Granger, P. NMR Nomenclaure. Nuclear Spin Properties and Conventions for Chemical Shifts (IUPAC Recommendations 2001). Pure Appl. Chem. 2001, 73 (11), 1795-1818.

(23) Kottler, C.; Döbeli, M.; Glaus, F.; Suter, M. A spectrometer for low energy heavy ion ERDA. Nucl. Instrum. Methods Phys. Res., Sect. B 2006, 248 (1), 155-162.

(24) Groszek, A. J. Selective Adsorption at Graphite/ Hydrocarbon Interfaces. Proc. R. Soc. London, Ser. A 1970, 314 (1519), 473-498.

(25) Handbook of Modern Ion Beam Materials Analysis: Materials Research Society: Pittsburgh, United States, 2009.

(26) Medek, A.; Harwood, J. S.; Frydman, L. Multiple-Quantum Magic-Angle Spinning NMR: A New Method for the Study of Quadrupolar Nuclei in Solids. J. Am. Chem. Soc. 1995, 117, 1277912787.

(27) Good, C. D.; Ritter, D. M. Alkenylboranes. II. Improved Preparative Methods and New Observations on Methylvinylboranes. J. Am. Chem. Soc. 1962, 84 (7), 1162-1166.

(28) Hwang, S.-J.; Chen, C.-Y.; Zones, S. I. Boron Sites in Borosilicate Zeolites at Various Stages of Hydration Studied by Solid State NMR Spectroscopy. J. Phys. Chem. B 2004, 108 (48), 1853518546.

(29) Kroeker, S.; Stebbins, J. F. Three-Coordinated Boron-11 Chemical Shifts in Borates. Inorg. Chem. 2001, 40 (24), 6239-6246.

(30) Thompson, R. J.; Davis, J. C. Electronegativity Effects on $B^{11}$ Chemical Shifts in Tetrahedral $\mathrm{BX}_{4}^{-}$Ions. Inorg. Chem. 1965, 4 (10), 1464-1467.

(31) Turner, C. L.; Taylor, R. E.; Kaner, R. B. ${ }^{10} \mathrm{~B}$ and ${ }^{11} \mathrm{~B}$ NMR Study of Elemental Boron. J. Phys. Chem. C 2015, 119 (24), 1380713813

(32) Vidano, R. P.; Fischbach, D. B.; Wills, L. J.; Loehr, T. M. Observation of Raman band shifting with excitation wavelength for carbons and graphites. Solid State Commun. 1981, 39 (2), 341-344.

(33) Ferrari, A. C.; Meyer, J. C.; Scardaci, V.; Casiraghi, C.; Lazzeri, M.; Mauri, F.; Piscanec, S.; Jiang, D.; Novoselov, K. S.; Roth, S.; Geim, A. K. Raman Spectrum of Graphene and Graphene Layers. Phys. Rev. Lett. 2006, 97, 187401.
(34) Ferrari, A. C.; Robertson, J. Interpretation of Raman spectra of disordered and amorphous carbon. Phys. Rev. B: Condens. Matter Mater. Phys. 2000, 61 (20), 14095-14107.

(35) Hach, C. T.; Jones, L. E.; Crossland, C.; Thrower, P. A. An investigation of vapor deposited boron rich carbon - a novel graphitelike material - part I: the structure of $\mathrm{BC}_{\mathrm{x}}\left(\mathrm{C}_{6} \mathrm{~B}\right)$ thin films. Carbon 1999, 37, 221-230.

(36) Krishnan, K. M.; Kouvetakis, J.; Sasaki, T.; Bartlett, N. Characterization of newly synthesized novel graphite films. MRS Online Proc. Libr. 1988, 121, 527-530.

(37) Krishnan, K. M. Structure of newly synthesized $\mathrm{BC}_{3}$ films. Appl. Phys. Lett. 1991, 58 (17), 1857-1859.

(38) Elman, B. S.; Dresselhaus, M. S.; Dresselhaus, G.; Maby, E. W.; Mazurek, H. Raman scattering from ion-implanted graphite. Phys. Rev. B: Condens. Matter Mater. Phys. 1981, 24 (2), 1027-1034.

(39) Naeini, J. G.; Way, B. M.; Dahn, J. R.; Irwin, J. C. Raman scattering from boron-substituted carbon films. Phys. Rev. B: Condens. Matter Mater. Phys. 1996, 54 (1), 144-151.

(40) Hishiyama, Y.; Irumano, H.; Kaburagi, Y.; Soneda, Y. Structure, Raman scattering, and transport properties of boron-doped graphite. Phys. Rev. B: Condens. Matter Mater. Phys. 2001, 63, 245406.

(41) Kim, D. P.; Labes, M. M. Formation of Graphite Flakes from Aromatic Precursors: A Comparison of Benzene- and TriphenyleneDerived Graphites. Chem. Mater. 1990, 2 (5), 599-603.

(42) Stevens, D. A.; Dahn, J. R. The Mechanisms of Lithium and Sodium Insertion in Carbon Materials. J. Electrochem. Soc. 2001, 148 (8), A803-A811.

(43) Irisarri, E.; Ponrouch, A.; Palacin, M. R. Review - Hard Carbon Negative Electrode Materials for Sodium-Ion Batteries. J. Electrochem. Soc. 2015, 162 (14), A2476-A2482.

(44) Balogun, M.-S.; Luo, Y.; Qiu, W.; Liu, P.; Tong, Y. A review of carbon materials and their composites with alloy metals for sodium ion battery anodes. Carbon 2016, 98, 162-178.

(45) Wang, H.; Li, Y.; Wang, Y.; Hu, S.; Hou, H. Highly Microporous Graphite-Like $\mathrm{BC}_{\mathrm{x}} \mathrm{O}_{3-\mathrm{x}} / \mathrm{C}$ Nanospheres for Anode Materials of Lithium-Ion Batteries. J. Mater. Chem. A 2017, 5, 2835-2843. 